\title{
Gastroenterology 2022: Groundhog Day
}

\author{
Oliver D Tavabie (D) , ${ }^{1}$ Jennie Clough, ${ }^{2}$ Aditi Kumar (D) ${ }^{3}$
}

${ }^{1}$ Department of Hepatology, Barts Health NHS Trust, London, UK

${ }^{2}$ Gastroenterology Department, Guy's and Saint Thomas' NHS Foundation Trust, London, UK ${ }^{3}$ Gastroenterology Department, Royal Wolverhampton Hospitals NHS Trust, Wolverhampton, UK

\section{Correspondence to}

Dr Oliver D Tavabie, Department of Hepatology, Barts Health

NHS Trust, London, UK; oliver. tavabie@nhs.net

Received 25 January 2022 Accepted 8 February 2022

\section{Check for updates}

(c) Author(s) (or their employer(s)) 2022. No commercial re-use. See rights and permissions. Published by BMJ.

To cite: Tavabie $O D$,

Clough J, Kumar A. Frontline

Gastroenterology Epub ahead

of print: [please include Day

Month Year]. doi:10.1136/

flgastro-2022-102111
Before the days of 'On Demand' television, winning the fight for the postChristmas lunch film was a big deal in my house. Once the Christmas pudding hit the table, each contender was pitched by a family member trying to win favour from the adjudicator (Mum). A famous win of mine was in the mid-90s fighting for 'Groundhog Day'. It remains a favourite film; not only because it has Bill Murray in it, but fundamentally, it is a heartwarming story about how you can learn by reflection to make the world a better place. With another surge in SARS-CoV-2 infections affecting the UK this Christmas, it feels like an appropriate time to reflect on what has changed since January 2021 and our future challenges in the ongoing pandemic. ${ }^{1}$

The international collaboration leading to the rapid development of numerous vaccines to SARS-CoV-2 infection has been a major success story. These vaccines have been shown to reduce the number and severity of infections. While there is evolving data regarding efficacy against new variants, it remains likely that mass vaccination will reduce the impact of the ongoing pandemic. ${ }^{2}$ However, we have observed suboptimal vaccine responses in some of our gastroenterology patient cohorts. Patients with inflammatory bowel disease (IBD) treated with infliximab were demonstrated to have attenuated antibody responses, ${ }^{3}$ as did patients post liver transplantation ${ }^{4}$ and those with chronic liver disease. ${ }^{5}$ Subsequently, the British Society of Gastroenterology (BSG) has recommended and advocated for booster dosing in these cohorts. ${ }^{6}$ As healthcare professionals, we have a duty to promote vaccination in our patient interactions and to continue to contribute to ongoing efforts determining optimal vaccine strategy for the benefit of our patients.
The beginning of the pandemic in 2020 led to a halt in all non-emergent care, including cancer services. Two years on, as the pandemic continues to ebb and flow, non-COVID medicine has clearly had to continue. Balancing both has been challenging leading to ever-growing waiting times for patients across specialties. $^{7}$ While undoubtedly more funding is required to support this 'catch-up', we need to continue to innovate to provide healthcare in a manner that is safe for us and our patients.

Telemedicine has historically not been utilised effectively in secondary care, but can be used to reduce the frequency for face to face appointments with good feedback from patients in IBD clinics. ${ }^{8}$ However, defining optimal cohorts for telemedicine remains a priority across Gastroenterology. Re-evaluating pathways to decentralise aspects of patient care will reduce waiting lists while also benefiting patients by reducing travelling times and taking unpaid time off work. This has been demonstrated to be possible in liver transplant where decentralisation of the transplant assessment to satellite centres led to comparable short-term patient outcomes to a central transplant centre. ${ }^{9}$ While long-term outcomes are awaited, it raises the question of what other services can be performed by local teams. Reducing the need for endoscopy is critical due to the growing waiting lists secondary to the response to the pandemic. ${ }^{10}$ Developing and validating non-invasive diagnostic tests, such as in coeliac disease, is essential as we move forward. ${ }^{11}$ Re-evaluating gastroenterology service provision to consider how we interact with patients, deliver services and diagnose and manage diseases will not only help in the recovery from the pandemic but allow us to make changes that are greener and more environmentally sustainable. ${ }^{12}$ 
Training has been detrimentally affected across specialties with gastroenterology being no exception. The recent BSG trainee survey demonstrated significant negative impacts across all aspects of training with notable reductions in endoscopy exposure. Given the shape of training driven reforms, the majority of trainees did not feel that they would be ready to be a consultant in this training model. ${ }^{13}$ This is of great concern. To ensure the next generation of gastroenterologists are competent and confident to perform their roles, we need to consider how we plan on providing and delivering effective and time-efficient training. Intensive periods of training without general medicine obligations may improve trainee competency. Immersive endoscopy training has been demonstrated to increase exposure without affecting patient outcome. ${ }^{14}$ Replicating this model in other gastroenterology areas is of interest as is evaluating the impact on medical service provision. Providing a structured framework for trainees to use in clinics, such as the non-alcoholic fatty liver disease bundle, ${ }^{15}$ not only standardises care for patients but provides an introduction for junior trainees to new conditions which they can build on. Using this approach in other areas may improve patient care and improve confidence of trainees in managing common pathology. Finally, the BSG trainee survey demonstrated significant negative impact of the pandemic on trainee research. ${ }^{13}$ Promoting schemes such as the National Institute for Health Research Associate Principal Investigator scheme ${ }^{16}$ as well as supporting trainee networks both regionally and nationally ${ }^{1718}$ will improve access and equity in opportunity to research opportunities for trainees across the UK. Research is the backbone of medicine and thus it is vital we cultivate a culture of innovation to improve patient care in the future.

When TV weatherman Phil Connors awakes on Groundhog Day on 2 February, he believes that he is in Punxsutawney for just 1 day before returning back to do better things with his life. While initially he feels trapped in time, it provides opportunity for him to grow and develop as a person (figure 1). Similarly, the last 2 years has felt like a never-ending loop of lockdowns and redeployments, undoubtedly placing great stress on ours and our patients' lives. However, we have also seen that in unprecedented times, we have the capability to adapt and be resilient while constantly

\footnotetext{
"When Chekhov saw the long winter, he saw a winter bleak and dark and bereft of hope. Yet we know that winter is just another step in the cycle of life. But standing here among the people of Punxsutawney and basking in the warmth of their hearths and hearts, I couldn't imagine a better fate than a long and lustrous winter."
}

Figure 1 Quotation from Phil Connors, Groundhog Day, 1993. striving to improve all aspects of the ways we work, learn and provide healthcare. Continue to send us your best stuff and we wish you all a productive 2022 .

Twitter Jennie Clough@jennie_clough and Aditi Kumar@ dr_dee_kumar

Contributors ODT wrote the initial draft. JC and AK provided critical revisions. All authors approved the final version.

Funding The authors have not declared a specific grant for this research from any funding agency in the public, commercial or not-for-profit sectors.

Competing interests All authors are trainee associate editors at Frontline Gastroenterology.

Patient consent for publication Not applicable.

Provenance and peer review Not commissioned; externally peer reviewed.

ORCID iDs

Oliver D Tavabie http://orcid.org/0000-0003-4693-6632

Aditi Kumar http://orcid.org/0000-0003-1026-3173

\section{REFERENCES}

1 Tavabie OD, Clough J. Gastroenterology 2021: from the heart of the COVID-19 pandemic. Frontline Gastroenterol 2021;12:249-51.

2 NHS. Coronavirus (COVID-19) vaccines. NHS, 2022. Available: https://www.nhs.uk/conditions/coronavirus-covid19/coronavirus-vaccination/coronavirus-vaccine/ [Accessed 18 Jan 2022].

3 Kennedy NA, Lin S, Goodhand JR, et al. Infliximab is associated with attenuated immunogenicity to BNT162b2 and ChAdOx1 nCoV-19 SARS-CoV-2 vaccines in patients with IBD. Gut 2021;70:1884-93.

4 Davidov Y, Tsaraf K, Cohen-Ezra O, et al. Immunogenicity and adverse effects of the 2-Dose BNT162b2 messenger RNA vaccine among liver transplantation recipients. Liver Transpl 2022;28:215-23.

5 Ai J, Wang J, Liu D, et al. Safety and Immunogenicity of SARS-CoV-2 Vaccines in Patients With Chronic Liver Diseases (CHESS-NMCID 2101): A Multicenter Study. Clin Gastroenterol Hepatol 2021. doi:10.1016/j.cgh.2021.12.022. [Epub ahead of print: 20 Dec 2021].

6 BSG. BSG - COVID-19 Guidance and Advice. BSG, 2022. Available: https://www.bsg.org.uk/covid-19-advice/ [Accessed 10 Jan 2022].

7 NHS England. Consultant-Led referral to treatment waiting times data 2021-22. NHS England, 2022. Available: https:// www.england.nhs.uk/statistics/statistical-work-areas/rtt-waitingtimes/rtt-data-2021-22/ [Accessed 17 Jan 2022].

8 Kumar Aet al. Insight from patients and healthcare professionals on the implementation of virtual clinics in patients with inflammatory bowel disease. Frontline Gastroenterol 2021:flgastro-2020-101714.

9 Pradeep A, Barker F, Ramos K, et al. Virtual liver transplant assessment: a novel pathway that is likely safe, effective and optimises access to transplantation. Frontline Gastroenterol 2021;19:flgastro-2021-101976.

10 Catlow J, Beaton D, Beintaris I, et al. JAG/BSG national survey of UK endoscopy services: impact of the COVID-19 pandemic and early restoration of endoscopy services. Frontline Gastroenterol 2021;12:272-8.

11 Beig J, Rostami K, Hayman DTS, et al. Is duodenal biopsy always necessary for the diagnosis of coeliac disease in adult patients with high anti-tissue transglutaminase (TTG) antibody titres? Frontline Gastroenterol 2021;4:flgastro-2020-101728.

12 Maurice JB, Rochford A, Marshall S, et al. Green endoscopy: using quality improvement to develop sustainable practice. Frontline Gastroenterol 2021;5:flgastro-2021-101874. 
13 Raju SA, Harris R, Cook C, et al. UK-wide study of the opinions of gastroenterology trainees: COVID-19, shape of training and the future workforce. Frontline Gastroenterol 2021;159:flgastro-2021-101965.

14 Adu-Tei S, Raju SA, Marks LJS, et al. Letter: enhancing training opportunities for upper Gi bleeding in Sheffield-a UK transferable model? Aliment Pharmacol Ther 2021;53:12412.

15 Neilson LJ, Macdougall L, Lee PS, et al. Implementation of a care bundle improves the management of patients with non-alcoholic fatty liver disease. Frontline Gastroenterol 2021;12:578-85.
16 National Institute for Health Research. Associate principal investigator (PI) scheme. NIHR, 2022. https://www.nihr.ac.uk/ health-and-care-professionals/career-development/associateprincipal-investigator-scheme.htm

17 Segal J, Widlak M, Ingram RJM, et al. What next for gastroenterology and hepatology trainee networks? lessons from our surgical colleagues. Frontline Gastroenterol 2022;13:flgastro-2021-101784

18 The trainee collaborative for research and audit in hepatology UK, ToRcH-UK: shining a light on liver disease in the UK. Frontline Gastroenterol 2021:1-2. doi:10.1136/ flgastro-2021-101948 